\title{
Thermal study on polyester networks based on the renewable monomers citric acid and gluconolactone
}

\section{Authors}

Patrick A.J.M. de Jongh ${ }^{a}$, Prem K.C. Paul ${ }^{b}$, Ezat Khoshdel ${ }^{b}$, Paul Wilson ${ }^{\text {a,c }}$, Kristian Kem$\mathrm{pe}^{\mathrm{c}, \mathrm{a}}$, and David M. Haddleton ${ }^{\mathrm{a} *}$

$=$

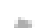

a Department of Chemistry, University of Warwick, CV4 7AL, Coventry, United Kingdom

${ }^{\mathrm{b}}$ Unilever Research, Port Sunlight, CH63 3JW, Bebington, United Kingdom

${ }^{\mathrm{c}}$ Monash Institute of Pharmaceutical Sciences, Monash University, Parkville, VIC 3052, Australia

\section{Corresponding author}

Corresponding author at: Department of Chemistry, University of Warwick, CV4 7AL, Coventry, United Kingdom.

Email address: D.M.Haddleton@warwick.ac.uk (D.M. Haddleton)

\section{Keywords}

Citric acid, gluconolactone, polyester, differential scanning calorimetry, renewable materials, glass transition temperature

\section{Abstract}

In this contribution, we present a detailed thermal study on the melt polycondensation between the renewable monomers citric acid and D-glucono- $\delta$-lactone. It was found that the polyester networks formed have glass transition temperature $\left(T_{g}\right)$ ranges that increase with This is the author manuscript accepted for publication and has undergone full peer review but has not been through the copyediting, typesetting, pagination and proofreading process, which may lead to differences between this version and the Version of Record. Please cite this article as doi: 
increasing reaction temperatures and time, corresponding to an increase in molecular weight. The minimum reaction temperature was investigated and found to be $130{ }^{\circ} \mathrm{C}$ for a 1/1 system. Moreover, the monomers show a eutectic melt behaviour, with a eutectic melting temperature of $125{ }^{\circ} \mathrm{C}$. A range of additional co-monomers were evaluated, revealing that aliphatic and aromatic bifunctional co-monomers result in lower glass transition temperatures. Where polyfunctional co-monomers were employed it was found that the chain flexibility influenced the resulting thermal properties. Moreover, it is shown that the ring-structure of D-glucono- $\delta$-lactone plays a key role in the thermal properties of the resulting polyesters.

\section{Introduction}

The majority of polyesters used commercially today are made from non-renewable fossil sources. As a result of fluctuating oil prices and their ultimate depletion, ${ }^{1}$ polyesters derived from renewable resources have attracted significant attention in recent years. ${ }^{2}$ In particular, their biodegradability, potential biocompatibility and the relatively easy access to biobased/biomass monomers makes them highly interesting next generation sustainable materials. Of all the polymers available from renewable resources polyesters stand out as the most available and versatile class. However, limiting this at the moment are the costs of biobased polyesters which are significantly higher than for petrochemical-based polyesters this will inevitably change in the future. ${ }^{3}$

In recent years an ever increasing list of monomers that can be obtained from biomass has been reported. ${ }^{4-6}$ An important subclass is the oxygen-rich monomers such as carboxylic acids, polyols, dianhydroalditols and furans. ${ }^{2}$ In a recent review, Vilela et al. highlighted succinic acid, fumaric acid, itaconic acid and furandicarboxylic acid as promising diacid, and isosorbide, isomannide, isoidide, 1,3-propanediol and 1,4-butanediol as diol monomers for the synthesis of polyesters. ${ }^{2}$

This article is protected by copyright. All rights reserved. 
A further interesting monomer is citric acid (CA), a tricarboxylic acid with a sterically hindered tertiary hydroxyl group. CA is a common metabolite of plants and animals and produced industrially by fermentation with Aspergillus Niger strains. ${ }^{7}$ Substrates for the production of CA include rapeseed oil, corncobs, and brewery wastes. ${ }^{8,9} \mathrm{CA}$ is the most commonly used polyacid monomer for the production of polyesters by melt polycondensation. In this context, it has been co-polymerised with various aliphatic diols, ${ }^{10-14}$ D-sorbitol ${ }^{15}$ and glycerol, ${ }^{16-19}$ amongst others. The polyester networks resulting from those reactions have found applications in for example tissue engineering ${ }^{20,21}$ and drug delivery. ${ }^{16,17}$

Apart from an easy access to monomers the safety of use of monomers is important to many applications. The US Food and Drug Administration has a database of 378 compounds that are generally recognised as safe (GRAS) as ingredients, for packaging and labelling. ${ }^{22}$ Some of these compounds have been used in the synthesis of polyesters, including citric acid, ${ }^{10-19}$ glycerol, ${ }^{16-19}$ lactic acid, ${ }^{23}$ malic acid, ${ }^{24-27}$ sorbitol, ${ }^{15}$ and sucrose ${ }^{28}$

In the context of using GRAS starting materials, Tsutsumi et al. investigated the polycondensation between CA and D-glucono- $\delta$-lactone (GL) in detail. ${ }^{29}$ Pre-polymers in molar ratios from CA/GL $4 / 1$ to $1 / 4$ were prepared by melt polycondensation at $165^{\circ} \mathrm{C}$, cast from a tetrahydrofuran solution and subsequently post-polymerised at $180{ }^{\circ} \mathrm{C}$. The resulting films were analysed for their thermal, mechanical, and physiochemical properties, as well as enzymatic degradation by Rhizopus delemar, which increased with increasing CA concentrations.

In this present study, we have further investigated the melt polycondensation between $\mathrm{CA}$ $\left(\mathrm{T}_{\text {melt }}=153^{\circ} \mathrm{C}\right)$ and $\mathrm{GL}\left(\mathrm{T}_{\text {melt }}=160^{\circ} \mathrm{C}\right)$ and the thermal properties of the resulting polyester networks. A "green", minimalistic approach was used in which reactions took place in the absence of solvent at temperatures just above the melting point of $\mathrm{CA}\left(\mathrm{T}_{\text {react }}=160{ }^{\circ} \mathrm{C}\right)$. The influence of reaction temperature and time was evaluated and a systematic study of different GRAS and relatively safe co-monomers was performed to provide more insight into this re- 
action and the factors that influence the reaction and material properties. By studying the reactions by differential scanning calorimetry (DSC), insight could be gained about both the reaction and the thermal properties of the resulting polyester networks simultaneously.

\section{Experimental}

\section{Materials}

Citric acid (CA, 99.5\%), D-glucono-ס-lactone (GL, 99\%), glycolic acid (GcA, 99\%), 1,1,1trimethylolpropane (TMP, 97\%), methylmalonic acid (MMA, 99\%), 2-hydroxyisobutyric acid (HIBA), DL-malic acid (MA, 99\%), L-tartaric acid (TA, 99\%), D-glucose (Glc, 99.5\%), Dfructose (Fru, 99\%), 4-hydroxybenzoic acid (HBA, 99\%), 1,3,5-trihydroxybenzene (THB, 99\%) and terephthalic acid (TPA, 98\%) were purchased from Sigma-Aldrich Co. LLC and used as received. L-lactic acid (LA, 98\%) was obtained from VWR International Ltd. and used as received. Glutaric acid (GtA, 99\%) and 1,6-hexanediol (HD, 97\%) were obtained from Merck Schuchardt OHG and used as received.

\section{Differential scanning calorimetry (DSC)}

Polymerisations and thermal analysis by DSC were performed on a Mettler Toledo DSC1 differential scanning calorimeter in $40 \mu \mathrm{L}$ aluminium crucibles. Data was processed using Mettler Toledo STARe software. The melting and reaction behaviour was determined from the first heating segment, the thermal properties of the formed polyester networks were evaluated on the second heating cycle. The heating programs used are specified below.

General polymerisation procedure

This article is protected by copyright. All rights reserved. 
Monomers were mixed in the solid state and ground for homogenisation, in molar ratios as stated in the main text (approximating 1/1 ratios between the functional groups). A small amount of $10-15 \mathrm{mg}$ was placed in a $40 \mu \mathrm{L}$ DSC crucible and subjected to the following DSC program (two heating/cooling cycles): $0-160-\mathrm{ITS}-0-160-0{ }^{\circ} \mathrm{C}$ at $5^{\circ} \mathrm{C} \mathrm{min}^{-1}$. The isothermal segment (ITS) on the first segment was set to $0,5,10$ or $20 \mathrm{~min}$ at $160^{\circ} \mathrm{C}$ to introduce different reaction times.

Determination of the minimum reaction temperatures for $C A$ and $G L$

$\mathrm{CA}$ and $\mathrm{GL}$ were mixed in a $1 / 1$ molar ratio and ground for homogenisation. A small amount of $10-15 \mathrm{mg}$ was placed in a $40 \mu \mathrm{L}$ DSC crucible and subjected to the following DSC program (two heating/cooling cycles): $0-\mathrm{T}_{\text {react }}-10 \mathrm{~min}$ ITS $-0-\mathrm{T}_{\text {react }}-0{ }^{\circ} \mathrm{C}$ at $5{ }^{\circ} \mathrm{C} \mathrm{min}^{-1}$. The reaction temperature $\left(T_{\text {react }}\right)$ was set at $70,90,110,130,150$ or $160{ }^{\circ} \mathrm{C}$.

Determination of the eutectic melting temperature of CA and GL

CA and GL were mixed in the solid state in various ratios from 10 to $90 \mathrm{~mol} \% \mathrm{GL}$ in $\mathrm{CA}$ and ground for homogenisation. A small amount of $10-15 \mathrm{mg}$ was placed in a $40 \mu \mathrm{L}$ DSC crucible and subjected to the following DSC program (two heating/cooling cycles): 0 - 160 $0-160-0{ }^{\circ} \mathrm{C}$ at $5{ }^{\circ} \mathrm{C} \mathrm{min}^{-1}$. The melt onset temperature for each monomer mixture was determined from the first heating cycle.

\section{Results and discussion}

Melt polycondensations between bi- and multifunctional monomers (Fig. 1) were studied by differential scanning calorimetry (DSC), analysing the melting and reaction characteristics on the first heating cycle and the thermal properties of the polyesters formed on the second heating cycle. At first, the standard system in this study, citric acid $\left(\mathrm{CA}, \mathrm{T}_{\text {melt }}=153^{\circ} \mathrm{C}\right)$ and 
D-glucono- $\delta$-lactone $\left(\mathrm{GL}, \mathrm{T}_{\text {melt }}=160^{\circ} \mathrm{C}\right.$ ) in a $1 / 1$ molar ratio was investigated. It was observed within the first heating cycle that the monomer mixture melts at a lower temperature than the individual monomers (Fig. 2A). The broad endothermic peak results from an impure mixture (both monomers act as an impurity to the other), as well as the reaction that takes place in the melt state.

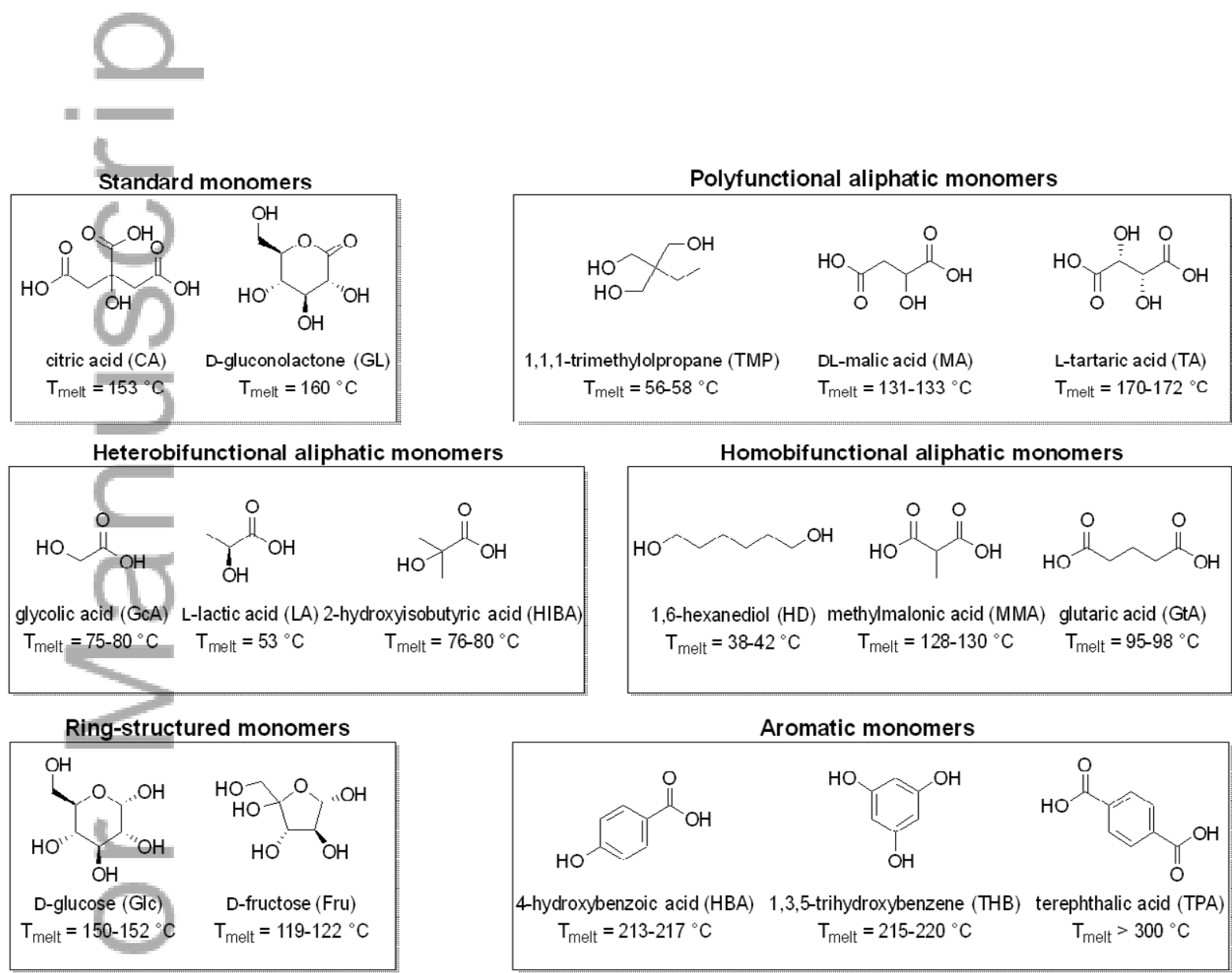

Figure 1. Monomers studied and their melting temperatures ( $\left.T_{\text {melt }}\right)$.

Within the second thermal cycle a glass transition at $17^{\circ} \mathrm{C}$ was observed. By introducing an isothermal segment (ITS) on the first cycle, between heating and cooling, the reaction time of the polycondensation could be changed. As expected for a polycondensation reac- 
tion, an increase in reaction time resulted in polymer networks with higher glass transition temperatures, increasing the $\mathrm{T}_{\mathrm{g}}$ up to $43{ }^{\circ} \mathrm{C}$ for a 20 min ITS (Fig. 2B). Similarly, when the reaction was performed at different temperatures the glass transition temperature increased with increasing reaction temperatures. A minimum reaction temperature of $130{ }^{\circ} \mathrm{C}$ was required to observe polyesters with a glass transition in the measurement range $\left(T_{g}=15^{\circ} \mathrm{C}\right)$ (Fig. 2C).

In-order to further investigate the lower melting temperature observed for the CA and GL mixture, a series of $C A+G L$ monomer mixtures was made with monomer ratios varying from 10 to $90 \mathrm{~mol} \% \mathrm{GL}$ in CA. Melt onset temperatures for all mixtures were found to be between 129 and $132{ }^{\circ} \mathrm{C}$, with the exception of the equimolar mixture which was found to be $125^{\circ} \mathrm{C}$. This shows that the CA and GL system has a eutectic melting behaviour, but with a small window to tune the melting temperature as they are close to each other (Fig. 2D). No relation was found between the monomer ratios or functional group ratios and the glass transition temperatures observed. This demonstrates that a temperature of only $125^{\circ} \mathrm{C}$ is required to melt the monomers at their eutectic composition, and a 10 min reaction at $130{ }^{\circ} \mathrm{C}$ already produces polyester networks with a glass transition temperature in the measurement window $\left(15^{\circ} \mathrm{C}\right)$

This article is protected by copyright. All rights reserved. 

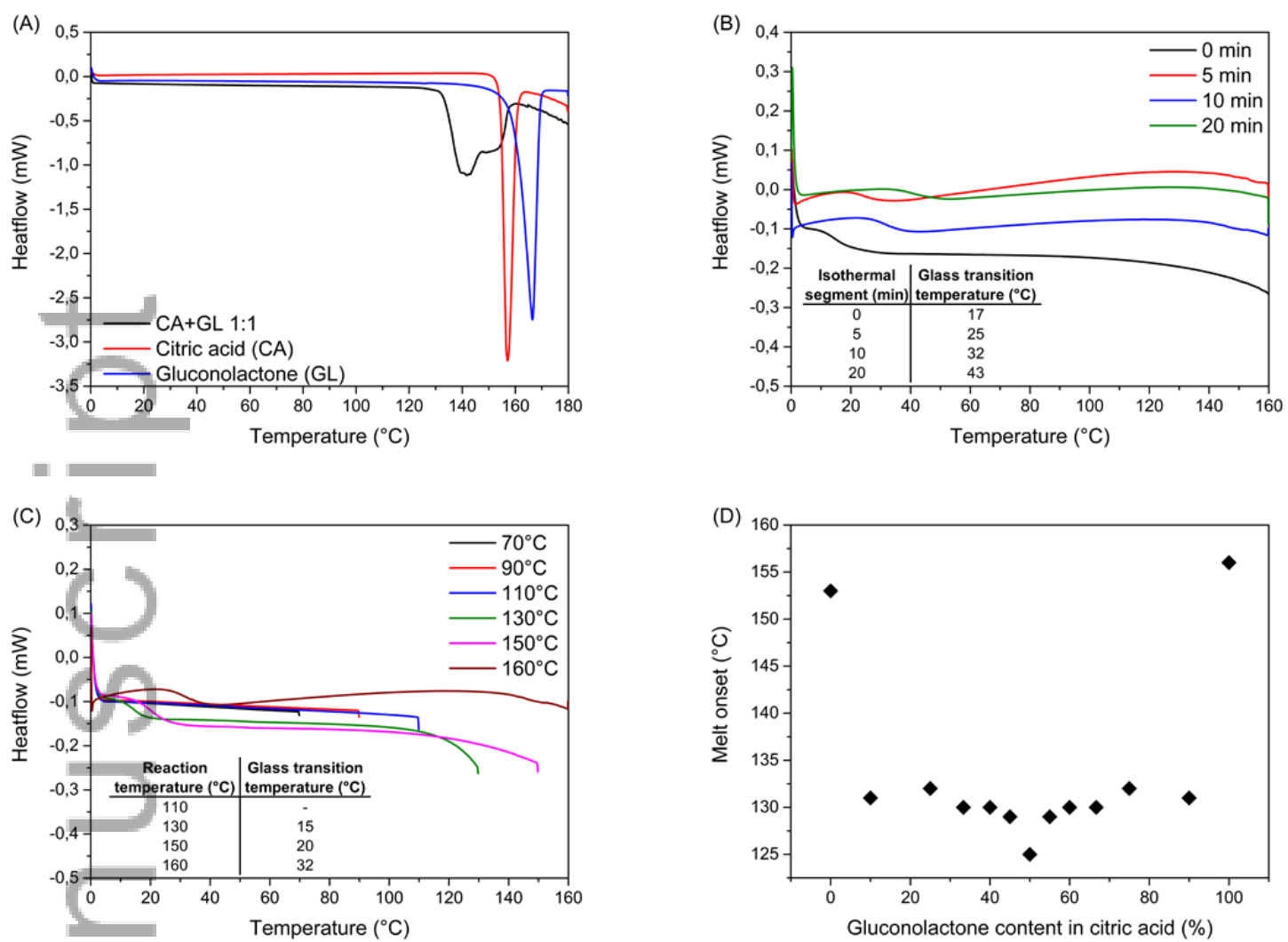

Figure 2. Polycondensation of citric acid (CA) and gluconolactone (GL) followed by DSC. (A) The reaction mixture of $C A$ and $G L(1 / 1)$ melts and reacts at a lower temperature than the individual monomers. (B) On the second heating cycle a glass transition temperature can be observed, which increases with increasing reaction time $\left(T_{\text {react }}=160^{\circ} \mathrm{C}\right) .(\mathrm{C})$ The glass transition temperature increases with increasing reaction temperatures, with a minimum of 130 ${ }^{\circ} \mathrm{C}$ required (10 min ITS). (D) The melt onset temperature of CA and GL mixtures reveals a eutectic melt behaviour.

A range of aliphatic, bifunctional co-monomers were studied with the objective of reducing the melting temperature of the monomer mixture while increasing the glass transition temperature of the polyester networks. For all multi-monomer systems, the molar ratios of monomers were chosen to keep the functional group stoichiometry approximately $1 / 1$ (ac- 
id/hydroxyl). Glycolic acid (GcA, $\mathrm{T}_{\text {melt }}=75-80{ }^{\circ} \mathrm{C}$ ) mixed in an equimolar ratio with $\mathrm{CA}$ and GL shows a sharp melting peak at the melting temperature of GcA (Fig. S1A). The CA and GL monomers do not completely dissolve in GcA at this point, but start to dissolve into, and react with, GcA just below $100{ }^{\circ} \mathrm{C}$. Within the second a cycle glass transition is observed, but at lower a temperature than the pure CA/GL system at the same reaction temperature and time (Fig. 3; Fig. S1B). Higher glass transition temperatures could be obtained by further increasing the reaction time.

It was hypothesised that these observations result from the introduction of linear segments through GcA. In order to investigate this, 1,6-hexanediol $\left(\mathrm{HD}, \mathrm{T}_{\text {melt }}=38-42{ }^{\circ} \mathrm{C}\right)$ was evaluated next. The first heating cycle looks similar, but now the co-monomer melts at 38-42 ${ }^{\circ} \mathrm{C}$ reacting with $\mathrm{CA} / \mathrm{GL}$ at $90{ }^{\circ} \mathrm{C}$ (Fig. S2A). Only for the 10 and 20 min reactions glass transition temperatures were observed (Fig. 3; Fig. S2B). This finding suggests that linear segments lower the glass transition temperature, as well as that a long flexible chain between the functional groups has a significant effect on the resulting material properties. This hypothesis is further confirmed by other bifunctional monomers: L-lactic acid (LA, $T_{\text {melt }}=53$ $\left.{ }^{\circ} \mathrm{C}\right)$, 2-hydroxyisobutyric acid $\left(\mathrm{HIBA}, \mathrm{T}_{\text {melt }}=76-80^{\circ} \mathrm{C}\right)$, methylmalonic acid $\left(\mathrm{MMA}, \mathrm{T}_{\text {melt }}=128-\right.$ $\left.130{ }^{\circ} \mathrm{C}\right)$ and glutaric acid $\left(\mathrm{GtA}, \mathrm{T}_{\text {melt }}=95-98^{\circ} \mathrm{C}\right)$, which all show lower glass transition temperatures, or no glass transition at all in case of $\mathrm{GtA}$, within the measured temperature range (Fig. 3; Fig. S3-6).

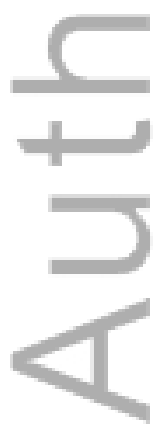

This article is protected by copyright. All rights reserved. 

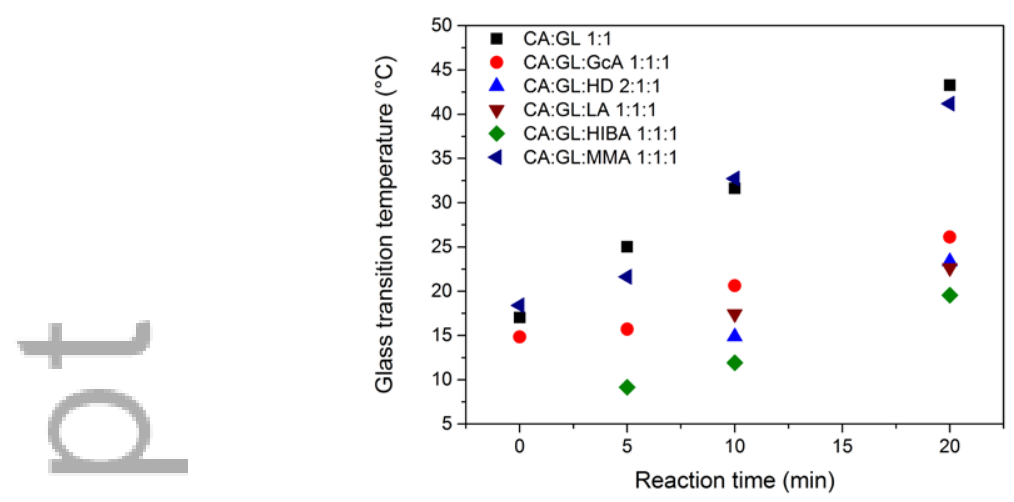

Figure 3. Glass transition temperatures for the polycondensation between citric acid (CA) and D-glucono- $\delta$-lactone $(G L)$ with aliphatic, bifunctional co-monomers: glycolic acid $(G c A)$, 1,6-hexanediol (HD), L-lactic acid (LA), a-hydroxyisobutyric acid (HIBA) and methylmalonic acid (MMA). Data points that are not shown indicate that there is no glass transition for that monomer in the measurement window $\left(0-160^{\circ} \mathrm{C}\right)$. The reaction time refers to the isothermal segment.

The observation of two endothermic melting events, one of the additional co-monomer and the other from dissolution and reaction of the other monomers, implies that the amount of co-monomer used can only dissolve a limited amount of CA and GL. Increasing the amount of co-monomer allows more CA and GL to be dissolved at low temperature, but only results in an increase in linear segments within the polyester networks and a decrease in their glass transition temperature (Fig. S7). This can in turn be overcome by elevated reaction temperatures or time (Fig. S8).

Subsequently, polyfunctional co-monomers were evaluated. 1,1,1-Trimethylolpropane $\left(\mathrm{TMP}, \mathrm{T}_{\text {melt }}=56-58^{\circ} \mathrm{C}\right)$ was tested in a CA/GL/TMP 2/1/1 ratio, and DL-malic acid (MA, $\mathrm{T}_{\text {melt }}$ $\left.=131-133^{\circ} \mathrm{C}\right)$ and L-tartaric acid $\left(\mathrm{TA}, \mathrm{T}_{\text {melt }}=170-172{ }^{\circ} \mathrm{C}\right)$ were tested in equimolar molar ratios with CA/GL. TMP showed a similar behaviour on the first heating cycle as the bifunc- 
tional co-monomers with a sharp melting peak at the melting temperature of TMP (Fig. S9A), followed by a further endothermic dissolution and reaction peak from $90{ }^{\circ} \mathrm{C}$. For MA and TA no separate co-monomer peak was observed (Fig. S10A and S11A), but only a broad endothermic melting and reaction peak, with melt onset temperatures at $118{ }^{\circ} \mathrm{C}$ and $130{ }^{\circ} \mathrm{C}$ for MA and TA, respectively. Glass transition temperatures increase in the order of TMP $<M A<$ TA (Fig. 4), which can be explained by the length and flexibility of chains between the reacting groups, which determines the crosslinking density.
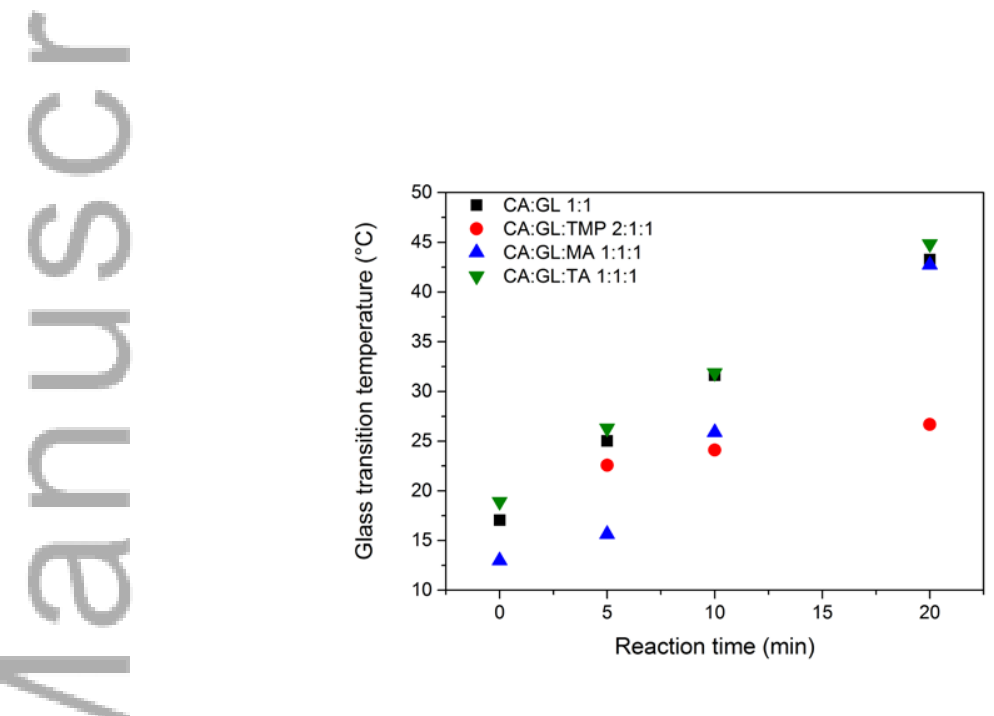

Figure 4. Glass transition temperatures for the polycondensation between citric acid (CA) and D-glucono- $\delta$-lactone (GL) with aliphatic, polyfunctional co-monomers: 1,1,1trimethylolpropane (TMP), DL-malic acid (MA) and L-tartaric acid (TA). The reaction time refers to the isothermal segment.

In addition to the aliphatic monomers tested, three aromatic monomers were also evaluated for the copolymerisation with CA and GL. 4-Hydroxybenzoic acid (HBA, $T_{\text {melt }}=213-217$ ${ }^{\circ} \mathrm{C}$ ) and terephthalic acid $\left(\mathrm{TPA}, \mathrm{T}_{\text {melt }}=300{ }^{\circ} \mathrm{C}\right.$ ) were copolymerised in equimolar ratios to $\mathrm{CA}$ and $\mathrm{GL} ; 1,3,5$-trihydroxybenzene $\left(\mathrm{THB}, \mathrm{T}_{\text {melt }}=215-220^{\circ} \mathrm{C}\right)$ was reacted in a $\mathrm{CA} / \mathrm{GL} / \mathrm{THB}$ $3 / 1 / 1$ molar ratio to have the same functional group stoichiometry. For short reaction times, 
all aromatic co-monomers resulted in glass transition temperatures close to the CA/GL system, but for long reaction times $(20 \mathrm{~min})$ it became clear that the trifunctional THB results in higher glass transition temperatures than the bifunctional HBA and TPA monomers (Fig. 5; Fig. S12-14).
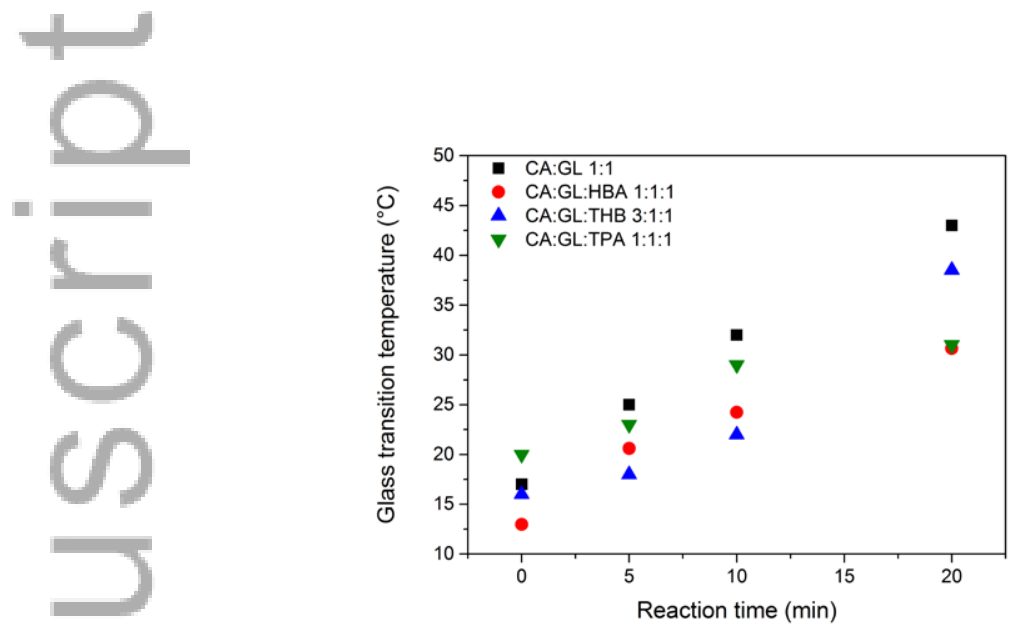

Figure 5. Glass transition temperatures for the polycondensation between citric acid (CA) and D-glucono- $\delta$-lactone (GL) with aromatic co-monomers: 4-hydroxybenzoic acid (HBA), 1,3,5-trihydroxybenzene (THB) and terephthalic acid (TPA). The reaction time refers to the isothermal segment.

To investigate the influence of the ring-structure of GL on the polyester networks, CA was copolymerised with D-glucose $\left(\mathrm{Glc}, \mathrm{T}_{\text {melt }}=150-152{ }^{\circ} \mathrm{C}\right)$ and D-fructose (Fru, $\mathrm{T}_{\text {melt }}=119-122$ ${ }^{\circ} \mathrm{C}$ ), in a $2 / 1 \mathrm{CA} /$ polyol ratio. Both monomer combinations were found to melt at lower temperatures than the individual monomers, with melt onset temperatures at 125 and $95{ }^{\circ} \mathrm{C}$ respectively for the Glc- and Fru-based systems (Fig. S15A and S16A). This is in line with a report that CA can form deep eutectic solvents (DES) with different sugars, including glucose and sucrose. ${ }^{30}$ The glass transition temperatures increased in the order of $\mathrm{Fru}<\mathrm{GL}<\mathrm{Glc}$ (Fig. 6). This can be explained structurally as fructose has two primary, and therefore more 
flexible, hydroxyl groups. Glucose has one more hydroxyl group than GL, on the anomeric position, providing another reactive position, compared to the GL monomer. When compared to the other polyfunctional co-monomers, this shows that the rigid structure of these polyols has a significant influence on the material properties, compared to monomers without a rigid ring structure, and that their modification has a higher impact on their glass transition temperature. The highest $\mathrm{T}_{\mathrm{g}}$ was found to be $55^{\circ} \mathrm{C}$ for a 20 min reaction with CA/Glu 2/1.
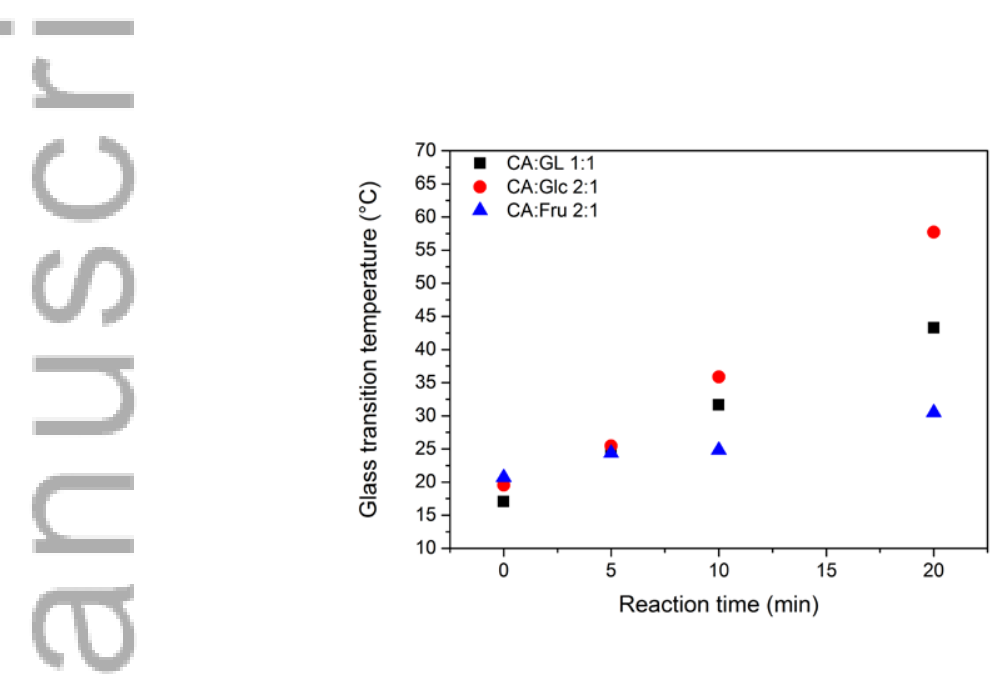

Figure 6. Glass transition temperatures for the polycondensation between citric acid (CA) different ring-structured polyol monomers: D-glucono-- $\delta$-lactone (GL), D-glucose (Glc) and Dfructose (Fru). The reaction time refers to the isothermal segment.

\section{Conclusions}

In this systematic study on polyester networks prepared by melt polycondensation from the renewable monomers citric acid and gluconolactone, it was first of all shown how reaction time and temperature influence the properties of the resulting networks. Increasing one or both yields materials with higher glass transition temperatures. Bifunctional monomers decrease this temperature, and even multifunctional monomers with flexible structures have the same result. It was found that aromatic co-monomers follow the same trend as aliphatic 
co-monomers. By evaluating other ring structured monomers it was shown how the rigid structure of gluconolactone has a significant influence on the resulting properties. The results in this study provide a general insight into this type of polycondensations and the results found can also be applied to polyester networks based on other materials.

\section{Acknowledgements}

The authors gratefully acknowledge financial support from Unilever PLC and the University of Warwick. DMH is a Royal Society/Wolfson Fellow.

\section{References}

1 M. Tsoskounoglou, G. Ayerides and E. Tritopoulou, Energ Policy 36:3797-3806 (2008).

2 C. Vilela, A. F. Sousa, A. C. Fonseca, A. C. Serra, J. F. J. Coelho, C. S. R. Freire and A. J. D. Silvestre, Polym Chem 5:3119-3141 (2014).

3 B. P. Mooney, Biochem J 418:219-232 (2009).

$4 \quad$ H. Kobayashi and A. Fukuoka, Green Chem 15:1740-1763 (2013).

5 R. T. Mathers, J Polym Sci A Polym Chem 50:1-15 (2012).

$6 \quad$ K. Yao and C. Tang, Macromolecules 46:1689-1712 (2013).

7 L. Karaffa and C. P. Kubicek, Appl Microbiol Biotechnol 61:189-196 (2003).

$8 \quad$ E. Alben and O. Erkmen, Food Technol Biotechnol 42:19-22 (2004).

9 M. Roehr, Food Technol Biotechnol 36:163-171 (1998).

10 Q. Chen, S. Liang and G. A. Thouas, Prog Polym Sci 38:584-671 (2013).

11 J. Yang, A. R. Webb and G. A. Ameer, Adv Mater 16:511-516 (2004).

12 J. Yang, A. R. Webb, S. J. Pickerill, G. Hageman and G. A. Ameer, Biomaterials 27:1889-1898 (2006).

13 Q. Liu, L. Jiang, R. Shi and L. Zhang, Prog Polym Sci 37:715-765 (2012).

14 R. T. Tran, Y. Zhang, D. Gyawali and J. Yang, Recent Pat Biomed Eng 2:216-227 (2009).

15 K. M. Doll, R. L. Shogren, J. L. Willett and G. Swift, J Polym Sci A Polym Chem 44:4259-4267 (2006).

16 M. Adeli, B. Rasoulian, F. Saadatmehr and F. Zabihi, J Appl Polym Sci 129:36653671 (2013).

17 S. Liu, M. Jiang, S. Ye, X. Xu, P. Lu and J. Dong, J Appl Polym Sci 124:3633-3640 (2011).

18 J. M. Halpern, R. Urbanski, A. K. Weinstock, D. F. Iwig, R. T. Mathers and H. A. von Recum, J Biomed Mater Res Part A 102:1467-1477 (2013).

19 B. Tisserat, R. H. O'kuru, H. Hwang, A. A. Mohamed and R. Holser, J Appl Polym Sci 125:3429-3437 (2012). 
20 I. Djordjevic, N. R. Choudhury, N. K. Dutta and S. Kumar, Polymer 50:1682-1691 (2009).

21 I. Djordjevic, N. R. Choudhury, N. K. Dutta and S. Kumar, Polym Int 60:333-343 (2011).

22 U.S. Food and Drug Administration, Generally Recognized as Safe (GRAS) http://www.fda.gov/Food/IngredientsPackagingLabeling/GRAS/default.htm (2015).

23 D. Garlotta, J Polym Environ 9:63-84 (2001).

24 C. Hahn, S. Wesselbaum, H. Keul and M. Möller, Eur Polym J 49:217-227 (2013).

25 T. Kajiyama, H. Kobayashi, K. Morisaku, T. Taguchi, K. Kataoka and J. Tanaka, Polym Degrad Stabil 84:151-157 (2004).

26 T. Kajiyama, T. Taguchi, H. Kobayashi, K. Kataoka and J. Tanaka, Polym Degrad Stabil 81:525-530 (2003).

27 = J. Telegdi, L. Trif, J. Mihály, E. Nagy and L. Nyikos, J Therm Anal Cal 121:663-673 (2015).

28 J. A. Galbis, M. de Gracia García-Martin, M. Violante de Paz and E. Galbis, Chem Rev 116:1600-1636 (2016).

29 N. Tsutsumi, M. Oya and W. Sakai, Macromolecules 37:5971-5976 (2004).

30 Y. H. Choi, J. van Spronsen, Y. Dai, M. Verberne, F. Hollman, I. W. C. E. Arends, G.J. Witkamp and R. Verpoorte, Plant Physiol 156:1701-1705 (2011).

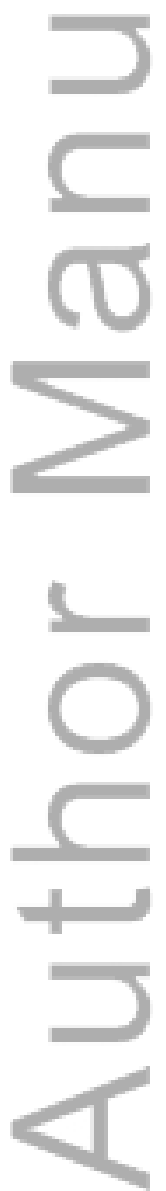

This article is protected by copyright. All rights reserved. 


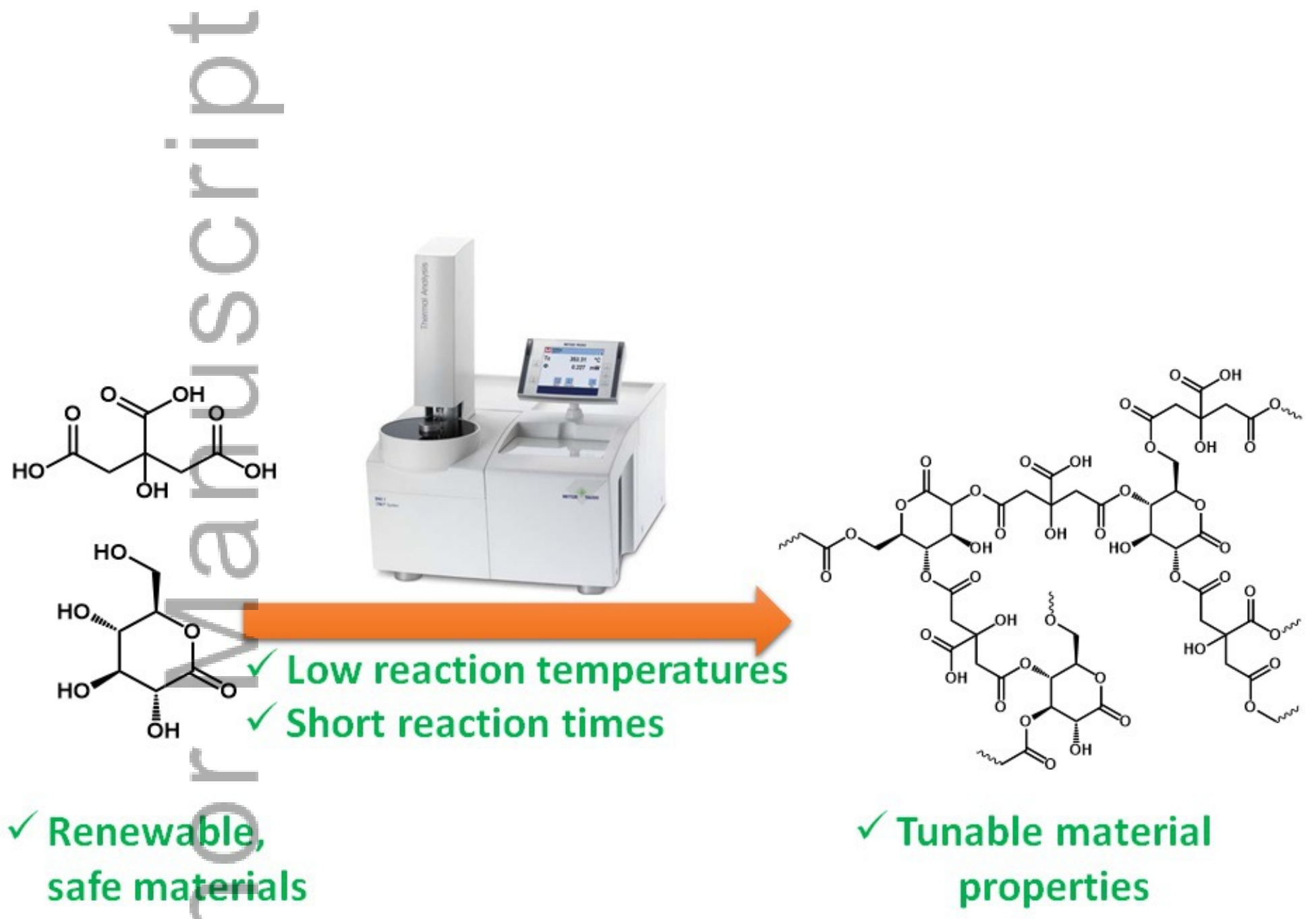

PI_5260_Graphical abstract 3.jpg 


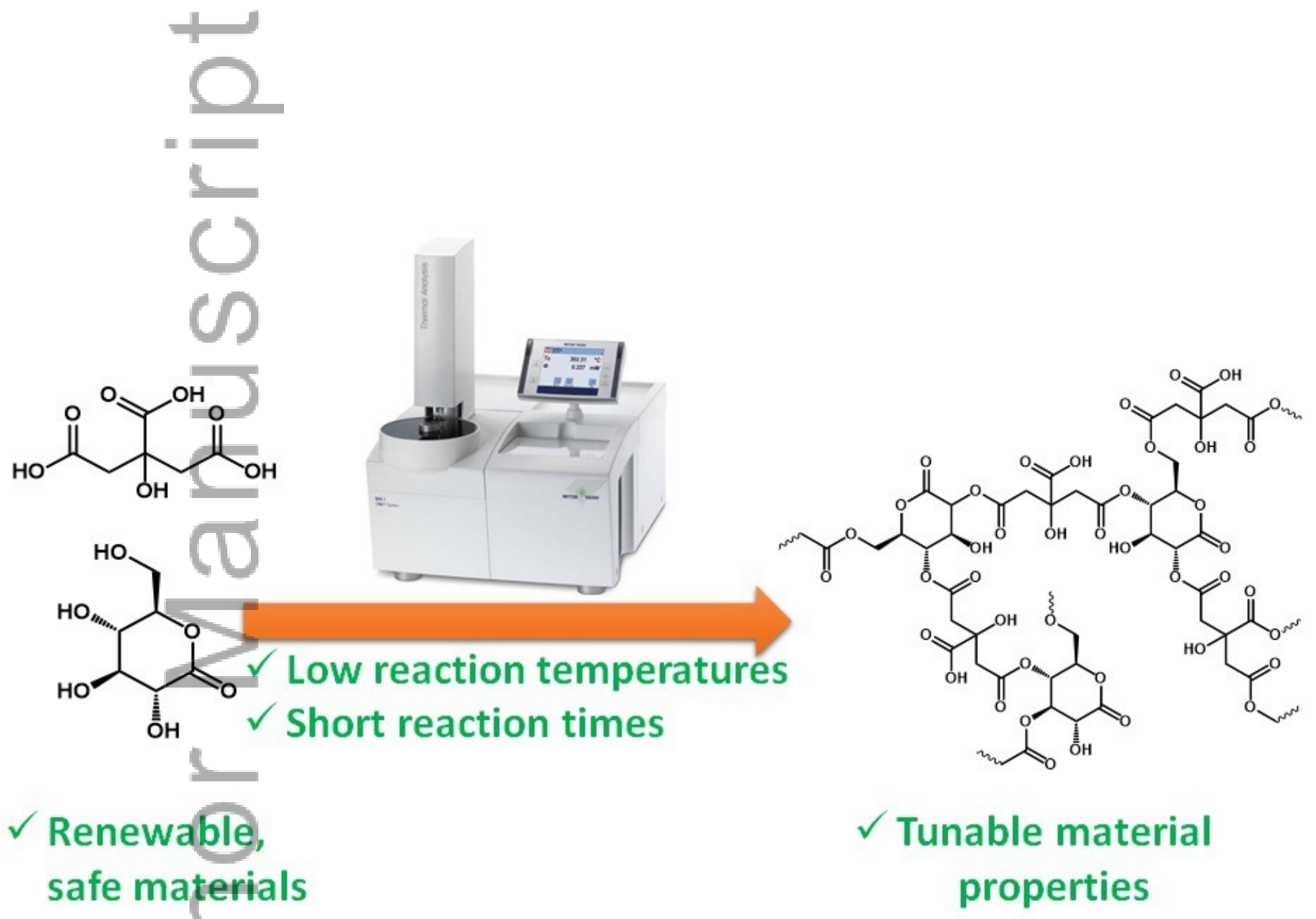

PI_5260_Graphical figure 3.jpg 


\section{University Library}

\section{- M M I N E R VA A gateway to Melbourne's research publications}

Minerva Access is the Institutional Repository of The University of Melbourne

\section{Author/s:}

de Jongh, PAJM;Paul, PKC;Khoshdel, E;Wilson, P;Kempe, K;Haddleton, DM

Title:

Thermal study of polyester networks based on renewable monomers citric acid and gluconolactone

Date:

2017-01-01

\section{Citation:}

de Jongh, P. A. J. M., Paul, P. K. C., Khoshdel, E., Wilson, P., Kempe, K. \& Haddleton, D. M. (2017). Thermal study of polyester networks based on renewable monomers citric acid and gluconolactone. Polymer International, 66 (1), pp.59-63. https://doi.org/10.1002/pi.5260.

Persistent Link:

http://hdl.handle.net/11343/291854 